E3S Web of Conferences 1, 19008 (2013)

DOI: $10.1051 / \mathrm{e} 3$ sconf/20130119008

(c) Owned by the authors, published by EDP Sciences, 2013

\title{
Rhizostabilzation of a mine tailing higly contaminated: Previous study of Cd localization and speciation in Anthyllis vulneraria
}

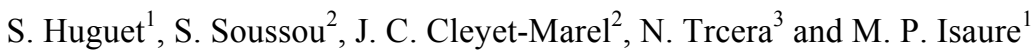 \\ ${ }^{1}$ Laboratoire de Chimie Analytique Bio-Inorganique et Environnement, Institut Pluridisciplinaire de Recherche sur \\ l'Environnement et les Matériaux (LCABIE/IPREM-UMR 5254), Université de Pau et des Pays de l'Adour, Hélioparc, 2 \\ Av. Pierre Angot, 64053 Pau Cedex 9, France. \\ ${ }^{2}$ Laboratoire des Symbioses Tropicales et Méditerranéennes, UMR 113 : IRD/CIRAD/SupAgro/UM2, USC 1242, \\ INRA, Campus International de Baillarguet, TA A-82/J, 34398 MONTPELLIER CEDEX 5, France. \\ ${ }^{3}$ Beamline LUCIA, Synchrotron SOLEIL, L'Orme des Merisiers, Saint-Aubin, BP 48, 91192 Gif-sur- Yvette Cedex, \\ France.
}

\begin{abstract}
The plant Anthyllis vulneraria has been identified in mine tailings and the aim of this study is to determine the mechanisms developed by the plant and its symbiotic association Mesorhizobium metallidurans to tolerate $\mathrm{Cd}$. We particulary intend to determine the distribution and speciation of $\mathrm{Cd}$ in plant using a combination of $\mu \mathrm{XRF}$ (X -ray fluorescence) and Cd XANES and $\mu$ XANES (X -ray Absorption Near Edge Structure).
\end{abstract}

Key words: Rhizostabilisation, Anthyllis vulneraria, Cadmium (Cd), Localization, Speciation

\section{Introduction}

Mine tailings are highly metal contaminated areas, which are strongly affected by intensive rain and wind erosion and thus represent a source of environmental and health hazard. Due to their large surface and high level of contamination, conventional remediation techniques are not appropriate, and phytostabilization has emerged as an alternative technique during the last decade (Arthur et al., 2005). In this technique, metal tolerant plants are used to reduce the metal mobility and to prevent the migration of contaminants to groundwater or air, and their entry in the food chain. In this context, it is necessary to find plants that tolerate metals, and in a longer term would serve as a direct or indirect source of nutrients in low organic mining soils, thus facilitating the installation of other species. This latter condition can be satisfied by legumes, which are associated in root to rhizobium nodules able to fix atmospheric nitrogen, and thus act as pioneer species. The legume Anthyllis vulneraria (subsp carpatica) was identified in a highly contaminated mine tailing from South of France (les Avinières mine) contaminated with $161000 \mathrm{ppm} \mathrm{Zn}$ and 1382 ppm Cd (Frérot et al., 2006). Interestingly, field experiments conducted in 2002 on the site showed that A. vulneraria progressively improved the biomass of grass species (Festuca) growing in its vicinity, thus promoting the revegetalization of the site (Frérot et al., 2006). Our general project focuses on the mechanisms developed by the symbiotic association Anthyllis vulneraria-Mesorhizobium metallidurans to tolerate Cd. A compartmentalization of the metal in specific organs/tissues as well as a binding with specific ligands may be a mechanism involved in metal tolerance. Hence, the specific objective of this present work is to determine $\mathrm{Cd}$ distribution and the ligands binding $\mathrm{Cd}$ in the leaves, roots of $A$. vulneraria as well as in its rhizobium nodules.

Micro X-ray absorption spectroscopy ( $\mu$ XAS) is a synchrotron based technique that has demonstrated great potential for the study of the chemical form of toxic trace metals in biological samples. Indeed, it is chemically selective, and the limits of detection are about ten $\mathrm{mg} \mathrm{kg}^{-1}$ of metal. In this work, XANES (X-ray Absorption Near Edge Structure) and $\mu$ XANES were applied to probe chemical and structural environment of $\mathrm{Cd}$ at the bulk and micrometer scales. Finally $\mu \mathrm{X}$-ray Fluorescence $(\mu \mathrm{XRF})$ was used to determine elemental distributions and associations.

\section{Materials and Methods}

Anthyllis vulneraria originated from Les Avinières were germinated and grown in hydroponics. Anthyllis 
population was well described by Frérot al. (2006) and Mahieu et al. (2011). Plants were inoculated with Mesorhizobium metallidurans. After nodulation, plants were exposed during four weeks to $\mathrm{Cd}$ present in two kind of substrate: (i) hydroponic solutions containing 10 or $70 \mu \mathrm{M} \mathrm{Cd}$, and (ii) soil from Les Avinières (50\%) mixed by attapulgite $(50 \%)$ and $70 \mu \mathrm{M} \mathrm{Cd}$. The addition of attapulgite was done in order to promote the nodulation. For both culture, aerial parts of plants were harvested and rinsed, roots and nodules were rinsed with a solution of $\mathrm{CaCl}_{2}(5 \mathrm{mM})$ and MilliQ Water and then separated.

\section{Cd concentrations}

For both experiments, one part of leaves and one parts of roots were oven-dried at $50^{\circ} \mathrm{C}$, ground and homogenised. Aliquots were digested in 1:1 volume $\mathrm{H}_{2} \mathrm{O}_{2}$ and $\mathrm{HNO}_{3}$ and filtered before analysis by ICP-MS (inductively coupled plasma - mass spectrometry). Quality control for plant samples was based on the use of certified standard samples (spinach leaves : SRM 1570a).

\section{Cd localization and speciation}

For both experiments, the other parts of leaves, and roots of Anthyllis vulneraria were frozen, ground in liquid nitrogen and prepared as frozen pressed pellets. Then, leaves and roots were analyzed by XANES as bulk samples. The other part of vegetal material frozen in liquid nitrogen was prepared as cross-sections using a cryomicrotome to investigate specific tissues of leaves (epidermis, mesophyll, veins), rhizobium nodules, and roots (xylem/phloem, endoderm, cortex, epidermis). Cd, $\mathrm{S}$, and $\mathrm{P}$ distribution were studied in these cross-sections using $\mu \mathrm{XRF}$. Then, $\mathrm{Cd}$ ligands were determined by $\mathrm{Cd}$ LIII-edge $\mu$ XANES recorded on various tissues of storage evidenced by $\mu \mathrm{XRF}$. The XANES and $\mu$ XANES spectra were then compared to spectra of modelcompounds including $\mathrm{Cd}$ minerals, Cd-sorbed minerals and Cd-complexed organic, already collected (Isaure et al., 2006, 2010), and fitted by linear combinations of these reference spectra. Chemical mapping and spectroscopy were performed on the beamline LUCIA (Soleil, Saclay, France) in cryogenic conditions to limit artefact from element redistribution and speciation change.

\section{Results and Discussion}

\section{Cd concentrations}

Cd concentrations in roots and leaves of Anthyllis grown on hydroponics were presented in table 1. As expected, in hydroponics, $\mathrm{Cd}$ concentration in roots and shoots increased with $\mathrm{Cd}$ exposure (around $1200 \mathrm{mg} \mathrm{Cd} \mathrm{kg}{ }^{-1}$ dry weight (DW) and $580 \mathrm{mg} \mathrm{kg}^{-1} \mathrm{DW}$ in roots for 70 and $10 \mu \mathrm{M} \mathrm{Cd}$, respectively, and 270 and $30 \mathrm{mg} \mathrm{Cd} \mathrm{kg}^{-1}$ DW in shoots, respectively) but interestingly, no acute toxicity sign in the plant physiology was observed. $\mathrm{Cd}$ concentrations measured in leaves and roots of plants grown on the soil from Les Avinières mixed with attapulgite and $70 \mu \mathrm{M}$ of $\mathrm{Cd}$ were intermediate and plants were healthy too. By comparison, Mahieu et al. (2011) measured $30.6 \pm 5.5 \mathrm{mg} \mathrm{Cd} \mathrm{kg}{ }^{-1} \mathrm{DW}$ in aerial parts of Anthyllis vulneraria inoculated by the same Mesorhizobium metallidurans grown in pot filled with soil from Les Avinières. Although the soil from Les Avinières was very contaminated (around 1200 and 165 $000 \mathrm{ppm}$ for $\mathrm{Cd}$ and $\mathrm{Zn}$ respectively), $\mathrm{Cd}$ and $\mathrm{Zn}$ are less phytoavailable than in hydroponics.

Table 1. Cd concentrations measured in aerials part of Anthyllis vulneraria grown on $\mathrm{Cd}$ enriched substrates (for hydroponics :average \pm standard deviation on $n=3$; for substrate with soil, $\mathrm{n}=1$ ).

\begin{tabular}{ccr}
\hline $\begin{array}{c}\text { Type of substrate } \\
\text { and content in Cd }\end{array}$ & $\begin{array}{c}\text { Cd concentrations }\left(\mathrm{mg} \mathrm{kg}^{-1} \mathrm{DW}\right) \\
\text { in leaves }\end{array}$ & \multicolumn{1}{c}{ in roots } \\
\hline $\begin{array}{c}\text { hydroponic soltuion with : } \\
10 \mu \mathrm{M} \mathrm{Cd} \\
70 \mu \mathrm{M} \mathrm{Cd}\end{array}$ & $30 \pm 2$ & $580 \pm 26$ \\
$\begin{array}{c}\text { soil Les Avinières + } \\
\text { attapulgite }+70 \mu \mathrm{M} \mathrm{Cd}\end{array}$ & 108 & $1236 \pm 79$ \\
\hline
\end{tabular}

\section{Cd speciation and localization in Anthyllis vulneraria}

Figure 1 shows the XANES spectra recorded on plant samples and on two $\mathrm{Cd}$ references: Cd-malate, as a representative of $\mathrm{Cd}-\mathrm{COOH} / \mathrm{OH}$ group with $\mathrm{Cd}-\mathrm{O} / \mathrm{N}$ bonds, and $\mathrm{Cd}$-cysteine as a representative of $\mathrm{Cd}$-thiols composed of $\mathrm{Cd}-\mathrm{S}$ bonds. On Cd-malate spectrum, the first peak is typical of Cd-O ligands. Cd LIII-edge XANES measurements performed on bulk leaves and roots for the $10 \mu \mathrm{M} \mathrm{Cd}$ treatment showed this peak. Thus, by comparison with reference spectra, $\mathrm{Cd}$ was mainly bound to $\mathrm{O} / \mathrm{N}$ ligands in these samples. On the contrary, S ligands seem dominant for plant samples exposed to the $70 \mu \mathrm{M} \mathrm{Cd}$ (Fig. 1). Cd exposure seemed to play a role in $\mathrm{Cd}$ speciation in leaves and roots samples. Verbruggen et al. (2009) reported that most of the hyperaccumulated metals are bound to ligands, such as organic acids, amino acids, peptides and proteins. Ligands depend on the metal, the function and the age of the plant tissue (Küpper et al., 2004). In mature and senescent leaves of Thlaspi caerulescens, oxygen ligands dominated and a fraction of the foliar $\mathrm{Cd}$ was bound to sulphur ligands. The detoxification of $\mathrm{Cd}$ by chelation in plants could involve thiol ligands such as glutathione, phytochelatines and metallothioneins (Verbruggen et al., 2009). Our results could highlight a probable toxicity in Anthyllis vulneraria exposed to $70 \mu \mathrm{M} \mathrm{Cd}$ and suggest a modification of the $\mathrm{Cd}$ sequestration form.

At the tissue scale, $\mathrm{Cd}$ was mainly bound to $\mathrm{S}$ in vascular bundles and in the nodules for the $10 \mu \mathrm{M}$ treatment (Fig. 1). In leaf, $\mathrm{Cd}$ seems to be transported as $\mathrm{Cd}-\mathrm{S}$ ligand, and possibly stored as $\mathrm{Cd}-\mathrm{O}$ ligand in the 


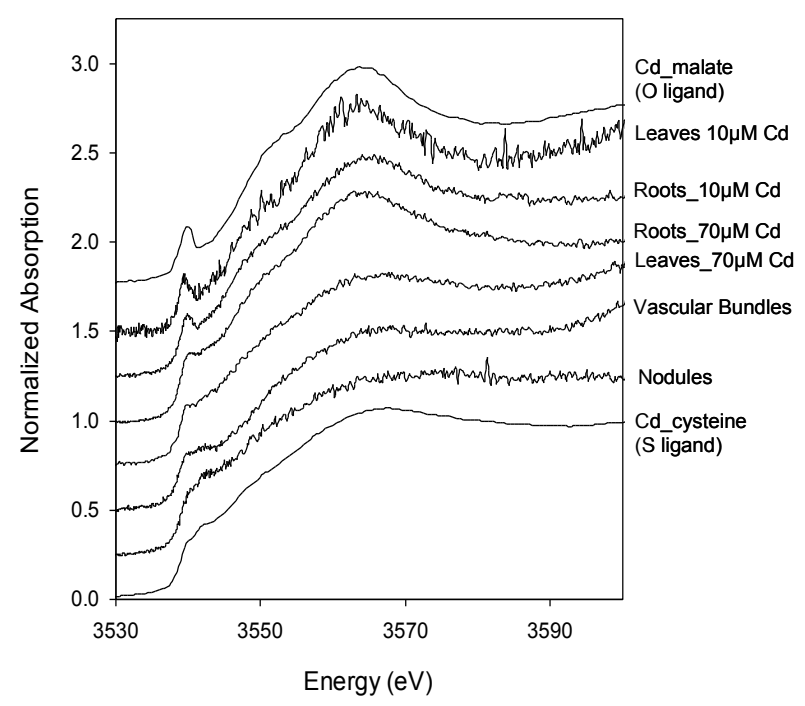

Fig. 1. Cd LIII -edge XANES spectra collected on bulk leaves and roots from $A$. vulneraria inoculated by rhizobium grown on 10 or $70 \mu \mathrm{M} \mathrm{Cd}$ and Cd LIII-edge $\mu$ XANES spectra collected in $\mathrm{Cd}$ enriched area of nodules and of vascular system of leaf of plant grown on $10 \mu \mathrm{M} \mathrm{Cd}$ (cf Fig. 2), compared to Cd references (Cdmalate and Cd-cysteine).

mesophyll. Will it be the same for $70 \mu \mathrm{M}$ treatment? To answer, work is in progress.

At leaf scale, in the central vein, $\mathrm{Cd}$ was colocalized with $\mathrm{P}$ and $\mathrm{S}$ (Fig. 2) and $\mathrm{Cd}$ was mainly in vascular bound regardless the culture substrate (hydroponics or soil mixed with attapulgite and with 70 $\mu \mathrm{M}$ Cd by hydroponic - maps not shown). In addition, $\mathrm{Cd}$ was found in trichomes and cells of epiderm (maps not shown). To our knowledge, there is no studies that report $\mathrm{Cd}$ localization at leaf scale in Anthyllis vulneraria, but there are data for other plants. In $A$. halleri, $\mathrm{Cd}$ is mostly accumulated in mesophyll cells (Kupper et al., 2000; Zhao et al., 2000). In T. praecox (Vogel-Mikŭs et al., 2008), Cd is more concentrated in the epidermis, but the mesophyll is still the major storage compartment due to its larger volume (Vogel-Mikŭs et al., 2008). Enrichments in $\mathrm{Cd}$ were observed for $A$. halleri ssp. gemmifera (Hokura et al., 2006; Fukuda et al., 2008) and $A$. thaliana (Isaure et al., 2006). In leaf, $\mathrm{Cd}$ storage sites seem depend on plant species.

\section{Acknowledgments}

This work was supported by the French National Research Agency "ANR CES" (Contaminants Ecosystemes Santé) founds through French research program SYMETAL (Rhizostabilisation of highly heavy metal contaminated mine spoils by using METALlicolous plants associated with microbial SYMbionts).

We thank Soleil, the French national synchrotron facility, for the provision of beamtime on the Lucia beamline.

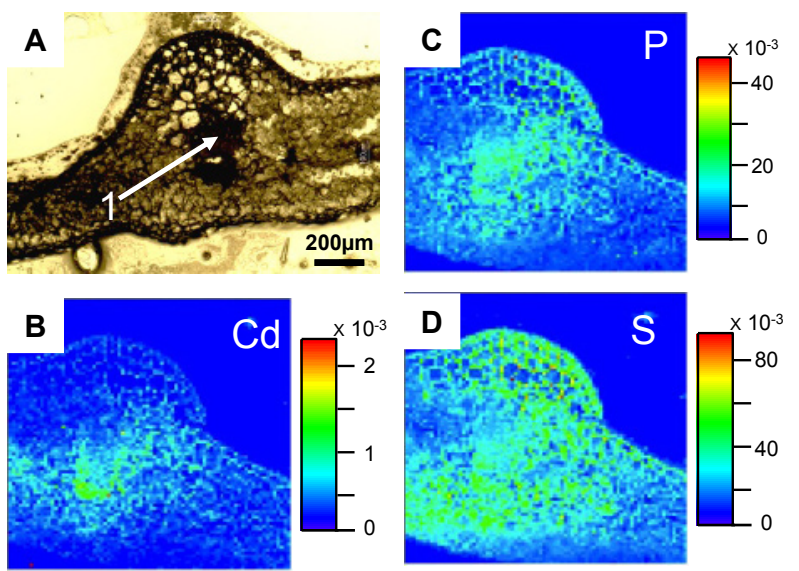

Fig. 2. (A) Cross-section of cenral vein of leaf of $A$. vulneraria exposed to $10 \mu \mathrm{M} \mathrm{Cd}$, observed by microscope showing vascular bundles (1) and (B, C, D respectively) elemental maps for $\mathrm{Cd}, \mathrm{P}$ and $\mathrm{S}$ of this section.

\section{References}

Arthur E.L., Rice P.J., Anderson T.A., Baladi S.M., Henderson K.L.D., and Coast J.R. 2005. Phytoremediation: an overview. Critical Reviews in Plant Sciences, 24, 109-122.

Frérot H., Lefèbvre C., Gruber W., Collin C., Dos Santos A., and Escarré J. 2006. Specific interactions between local metallicolous plants improve the phytostabilization of mine soils. Plant and Soil, 282, 53-65.

Fukuda N., Hokura A., Kitajima N., Terada Y., Saito H., Abed T., Nakai A. 2008. Micro X-ray fluorescence imaging and micro X-ray absorption spectroscopy of cadmium hyper-accumulating plant, Arabidopsis halleri ssp. gemmifera, using high-energy synchrotron radiation. Journal of Analytical Atomic Spectrometry 23, 1068-1075.

Hokura A., Onuma R., Kitajima N., Terada Y., Saito H., Abed T., Yoshida S., Nakai I. 2006. 2-D X-ray fluorescence imaging of cadmium hyperaccumulating plants by using high-energy synchrotron radiation X-ray microbeam. Chemistry Letters 826 35, 1246-1247.

Isaure MP, Fayard B, Sarret G, Pairis S, Bourguignon J. 2006. Localization and chemical forms of cadmium in plant samples by combining analytical electron microscopy and X-ray spectromicroscopy. Spectrochimica Acta- Part B Atomic Spectroscopy, 61, 1242-1252.

Isaure MP, Sarret G, Harada E, Choi YE, Marcus MA, Fakra SC, Geoffroy N, Pairis S, Susini J, Clemens S, Manceau A (2010) Calcium promotes cadmium elimination as vaterite grains by tobacco trichomes. Geochimica et Cosmochimica Acta, 74, 5817-5834.

Küpper H., Lombi E., Zhao F.J., McGrath S.P. 2000. Cellular compartmentation of cadmium and zinc in 
relation to other elements in the hyperaccumulator Arabidopsis halleri. Planta 212, 75-84.

Küpper H., Mijovilovich A., Meyer-Klaucke W., Kroneck P.M. 2004. Tissue- and age-dependent differences in the complexation of cadmium and zinc in the cadmium/zinc hyperaccumulator Thlaspi caerulescens (Ganges ecotype) revealed by x-ray absorption spectroscopy. Plant Physiology 134: 748-757.

Mahieu S., Frérot H., Vidal C., Galiana A., Heulin K., Maure L., Brunel B., Lefèbvre C., Escarré J. and Cleyet-Marel J.C. 2011. Anthyllis vulneraria/Mesorhizobium metallidurans, an efficient symbiotic nitrogen fixing association able to grow in mine tailings highly contaminated by $\mathrm{Zn}$, $\mathrm{Pb}$ and Cd. Plant Soil 342: 405-417.

Verbruggen N., Hermans C., Schat H. 2009. Molecular mechanisms of metal hyper-accumulation in plants. New Phytologist 181, 759-776.

Vogel-Mikŭs K., Regvar M., Mesjasz-Przybylowicz J., Przybylowicz W.J., Simcic J., Pelicon P., Budnar M. 2008. Spatial distribution of cadmium in leaves of metal hyperaccumulating Thlaspi praecox using micro-PIXE. New Phytologist 179, 712-721

Zhao F.J., Lombi E., Breedon T., McGrath S., 2000. Zinc hyperaccumulation and cellular distribution in Arabidopsis halleri. Plant, Cell \& Environment 23, 507-514. 